\title{
Prevalance of Pre-Eclampsia and Factors Responsible among Third Trimester Pregnant Women in Hospital of Dhaka
}

\author{
Khadija Akter $^{1}$ and Hamida Khanum ${ }^{2 *}$ \\ ${ }^{1}$ Azimpur Maternity Clinic, Dhaka \\ ${ }^{2}$ Parasitology Branch, Department of Zoology, University of Dhaka, Dhaka, Bangladesh \\ *Corresponding author: Hamida Khanum, Department of Zoology, University of Dhaka, Dhaka-1000, Bangladesh
}

\section{ARTICLE INFO}

Received: 幽 February 01, 2021

Published: 慧 February 08, 2021

Citation: Khadija Akter, Hamida Khanum. Prevalance of Pre-Eclampsia and Factors Responsible among Third Trimester Pregnant Women in Hospital of Dhaka. Biomed J Sci \& Tech Res 33(4)-2021. BJSTR. MS.ID.005445.

Keywords: Prevalence; Pre-eclampsia; Third trimester; Risk factors; Fetal mortality

\begin{abstract}
The present study was conducted in the Department of Obstetrics and Gynaecology of a tertiary care hospital in Dhaka, Bangladesh, during 2018. A total number of pregnant women with pre-eclampsia who admitted in this hospital were selected as study group. This was Analytical type of Cross-sectional study. Most of the participants were within 21-30 years of age group. The factors that were found to be significant predictors of risk for development of PE were primi-gravida, low socio- economic condition, family history of PE and hypertension, past history of PE and hypertension, past history of diabetes mellitus was also associated with development of PE. The study found that the primigravida, past history of PE, hypertension, diabetes mellitus family history of PE, hypertension and obesity are the major risk factors for PE. A checklist containing all the risk factors is to be asked routinely in antenatal checkup to prevent the development of PE.
\end{abstract}

\section{Introduction}

Pre-eclampsia (PE) is an idiopathic disorder of pregnancy characterized by proteinuric hypertension and still one of the most important causes of maternal and fetal mortality. Preeclampsia is a condition during pregnancy where there is a sudden, sharp rise in blood pressure, edema, and albuminuria. It generally develops during the third trimester and affects about 1 in 20 pregnancies [1]. In severe disease there may be red blood cell breakdown, a low blood platelet count, impaired liver function, kidney dysfunction, swelling, shortness of breath due to fluid in the lungs, or visual disturbances [2]. Pre-eclampsia (PE) is an idiopathic disorder of pregnancy, characterized by proteinuric hypertention. It is still one of the important causes of maternal and fetal mortality. In developed countries, deaths from hemorrhage and infection have almost disappeared and eclampsia has become the prime killer, indicating that death from eclampsia is particularly difficult to prevent.

WHO estimates incidence of pre-eclampsia, to be seven times higher in developing countries, $2.4 \%$ of live birth) than in developed countries (4\%). Approximately 289,000 women died globally from pregnancy-related causes in 2016. Of which, $99 \%$ of deaths occur in developing nations. Sub-Saharan Africa accounts for about $56 \%$ of all maternal deaths [3]. According to World Demographic and Health Survey report (2011), estimated 676 women per 100,000 live births were dying of pregnancy and related causes. Sixty to eighty percent of all maternal deaths are due to five major complications-namely, postpartum hemorrhage, puerperal sepsis, Hypertension disorder of pregnancy, unsafe abortion and obstructed labor [4].

Unmanaged preeclampsia can prevent a developing fetus from getting enough blood and oxygen, damage a mother's liver and kidneys, and, in rare cases, progress to eclampsia, a much more serious condition involving seizures [5,6]. Hypertensive Disorder of Pregnancy (HDP) is one of the leading causes of maternal mortality and maternal mortality (12.3\%) occurred from hypertension disorder of pregnancy. Moreover, $16 \%$ of direct maternal mortality and $10 \%$ of all maternal mortality was due to preeclampsia/ 
eclampsia. It is alarming that the rate of preeclampsia has increased in worldwide especially in developed countries by $40 \%$ between 1990 and 1999 due to an increase in number of older mothers and multiple births, increase the risk of preeclampsia [7].

Risk factors for pre-eclampsia include obesity, prior hypertension, older age, and diabetes mellitus. The underlying mechanism involves abnormal formation of blood vessels in the placenta amongst other factors. Most cases are diagnosed before delivery [8]. While historically both high blood pressure and protein in the urine were required to make the diagnosis [8]. The Bangladesh Maternal Mortality Survey (BMMS, 2010) revealed that eclampsia is the second most common direct cause of maternal death in Bangladesh followed by post-partum hemorrhage (PPH); it is responsible for about 20 percent of all maternal deaths. Among the 5,000 to 6,000 maternal deaths each year in Bangladesh, 1,000 to 1,200 are due to eclampsia. The findings indicated that family planning, by decreasing the likelihood of pregnancy after age 35 and parity four can help reduce the proportion of women at risk of maternal mortality [9].

\section{Maternal Mortality in Rural Bangladesh}

Oral iron intake is the treatment of choice and almostall pregnant women can be treated effectively with oral iron preparation during their pregnancy period. The previously presented evidence also strongly suggested that yearly check-ups for women with previous GDM were inevitably important. Maine and Rosenfield (1985) reviewed the available options and propose a strategy based on improving the availability and quality of medical treatment of obstetric complications. Substantial reductions in maternal deaths would be possible in a relatively short period of time if this strategy were embraced. In year 2005, Sibai et al. [10] investigated about the development of eclampsia that is associated with increased risk of adverse outcome for both mother and fetus, particularly in the developing nations.

Pre-eclampsia occurs when a woman experiences a rapid elevation of blood pressure to $>140 / 90 \mathrm{mmHg}$ (hypertension) and increased levels of protein in the urine (significant proteinuria $>0.3 \mathrm{~g} /$ day or $>30 \mathrm{mg} / \mathrm{mmol}$ of urinary creatinine in random sample) after 20 weeks gestation. Diagnosing pre-eclampsia and managing it before it progresses to severe pre-eclampsia or eclampsia is critical for improving maternal and newborn survival. WHO [11] recommends three main evidence-based approaches to prevent maternal mortality from PE/E. Although eclampsia is the third major cause of maternal death in Bangladesh, it is the major cause in our hospitals [12]. Management of the disease requires a clear understanding of all the associated factors. Further studies can be conducted involving etiological factors and pathogenesis of preeclampsia. Pregnancy related complications are still major problems in Bangladesh even though Bangladesh is well on its way towards achieving the Millennium Development Goal 5 (Improving maternal Health). Due to lack of proper facilities, awareness and education on these complications are extremely important to improving maternal health further.

Pre-eclampsia is a condition during pregnancy where there is a sudden, sharp rise in blood pressure, swelling (edema), and albuminuria (excess protein albumin leaks into the urine). Swelling tends to occur in the face, hands, and feet. It is the most common complication to occur during pregnancy. It generally develops during the third trimester and affects about 1 in 20 pregnancies (Davies). In severe disease there may be red blood cell breakdown, a low blood platelet count, impaired liver function, kidney dysfunction, swelling, shortness of breath due to fluid in the lungs, or visual disturbances [2]. Pre-eclampsia increases the risk of poor outcomes for both the mother and the baby. If left untreated, it may result in seizures at which point it is known as eclampsia.

Approximately 289,000 women died globally from pregnancyrelated causes in 2016. Of which, 99\% of deaths occur in developing nations. Sub-Saharan Africa accounts for about $56 \%$ of all maternal deaths [3]. A woman's lifetime risk of dying from pregnancy-related complications in developing countries is 14 times higher than in developed countries. According to World Demographic and Health Survey (2011) report, an estimated 676 women per 100,000 live births were dying of pregnancy and related causes. Sixty to eighty percent of all maternal deaths are due to five major complicationsnamely, postpartum hemorrhage, puerperal sepsis, Hypertension disorder of pregnancy, unsafe abortion and obstructed labor [4].

An estimated 8 to 10 percent of pregnant women are diagnosed with preeclampsia - though half of those cases are among those who had high blood pressure prior to pregnancy. Unmanaged preeclampsia can prevent a developing fetus from getting enough blood and oxygen, damage a mother's liver and kidneys, and, in rare cases, progress to eclampsia, a much more serious condition involving seizures [5]. With appropriate and prompt treatment, a woman with preeclampsia near term has virtually the same excellent chance of having a positive pregnancy outcome as a woman with normal blood pressure $[6,13]$. Hypertensive Disorder of Pregnancy (HDP) is one of the leading causes of maternal mortality and morbidity amongst pregnant women in the world. The World Health Organization [11] estimates of maternal death due to HDP were $25.7 \%$ in Latin-American and Caribbean, and 9.1\% in Asian and African countries. A study conducted in Ghana revealed that pregnancy.

WHO estimated the incidence of preeclampsia to be seven times higher in developing countries than developed countries. A study found that $12.3 \%$ maternal mortality occurred from hypertension disorder of pregnancy. A statistics showed that preeclampsia contributed for the complication of approximately $1 \%$ of all deliveries and $5 \%$ of all pregnancies. Moreover, $16 \%$ of direct maternal mortality and $10 \%$ of all maternal mortality (direct and in direct) was due to preeclampsia/eclampsia induced hypertension has contributed for $8.9 \%$ maternal mortality. In severe cases it 
can develop into eclampsia, or convulsive fits, which account for up to 10 percent of maternal deaths. A maternal mortality trend analysis showed an increasing trend of preeclampsia in developing countries [7]. Hypertensive disorder of pregnancy has remained a significant global public health threat in both developed and developing countries that contribute to maternal and perinatal morbidity and mortality.

Risk factors for pre-eclampsia include obesity, prior hypertension, older age, and diabetes mellitus. It is also more frequent in a woman's first pregnancy and if she is carrying twins. The underlying mechanism involves abnormal formation of blood vessels in the placenta amongst other factors. Most cases are diagnosed before delivery [8]. Blood pressure is defined as high when it is greater than $140 \mathrm{mmHg}$ systolic or $90 \mathrm{mmHg}$ diastolic at two separate times, more than four hours apart in a woman after twenty weeks of pregnancy. Preeclampsia is routinely screened for during prenatal care [8]. The factors associated with developing preeclampsia means that pregnant with preeclampsia not only have shorter life expectancy than women without preeclampsia but also experience poorer health related quality of life than the general population. Patients with preeclampsia, however, develop complications gradually; by the time they reach the hospital, complications have become so severe that they cannot be reversed easily [14]

\section{Justification of the Study}

A systematic review by the World Health Organization indicates that hypertensive disorders account for $16 \%$ of all maternal deaths in developed countries. Eclampsia is the third major cause of maternal death in Bangladesh (16\%), preceded by hemorrhage and sepsis. The identification of its predisposing factors before and during early stage of pregnancy will help in reducing the mortality.

\section{Materials and Methods}

The study was conducted in Azimpur Maternity Clinic and designed as analytical type of Cross-sectional study. Therefore, it can be helpful to describe the current conditions and situations based on the impressions and views of the respondents of the study (Thomas, 2005). The general objective of the present study were, to determine the risk factors for pre-eclampsia among pregnant women in a tertiary level hospital in order to identify factors associated with preeclampsia, the clinical and reproductive factors that may have relationship in developing preeclampsia. The target population are those who (236) visited Clinic during their 3rd trimester pregnancy within the age group 20 to 45 year.

The study was carried out during 2018. Data was collected by use of a standardized questionnaire and it contained both open-ended and closed-ended questions in order to get in-depth responses with clarity to meet the designed objectives for the study. Anthropological measurement will be checked for validation and reliability by Cronbach's alpha. Chi square test was done between categorical variables to show the association between dependent and independent variables. Logistic regression was done for multi variants analysis to control the potential confounding factors.

\section{Ethical Considerations}

The required permission was taken by the Ethical Review Committee of American International University-Bangladesh (AIUB) for the MPH course research and selected Hospital also.

\section{Results and Discussion}

The study was conducted on 260 3rd trimester pregnant women who visited Azimpur Maternity Clinic, Dhaka during the study period. Among the women $44 \%$ were suffering from preeclampsia, a condition in pregnancy characterized by high blood pressure, sometimes with fluid retention and proteinuria. The age range of these women was divided into three categories shown in Figure 1, where $9 \%$ respondents were below 20 years, $75 \%$ were 20 to 29 years and about $16 \%$ were in 30 years and above (Figure 1). In the present study, it was observed that more than half (51.85\%) of the respondents with age less than 20 years were suffering from complications. Age group with 20 to 29 years $(74.22 \%)$ was suffering from complications and pregnant women with age 30 years and above $75 \%$ patients were facing with complications (Figure 2).

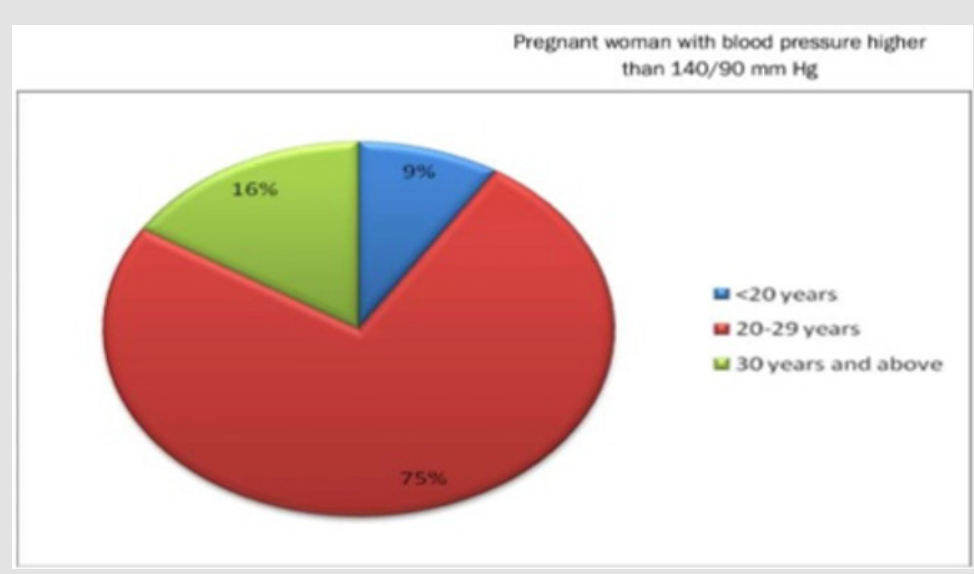

Figure 1: Different age groups of sample population. 


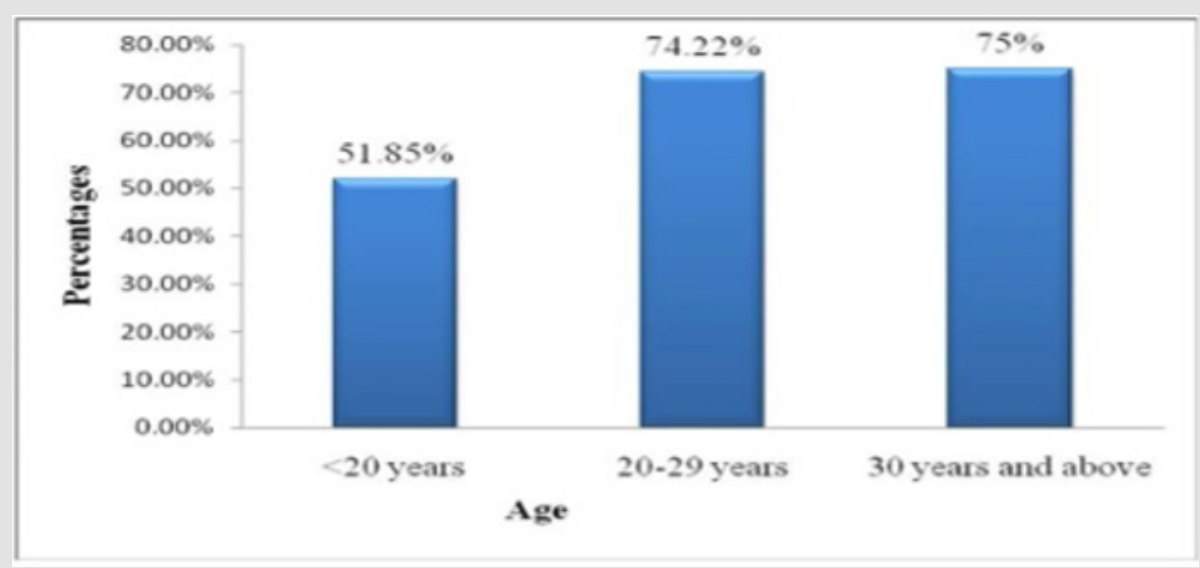

Figure 2: Patients with different complications within different age groups of population.

\section{Educational Status of the Respondents}

Levels of education of the respondents were classified as Illiterate, Primary, SSC, HSC, Under Graduate, Graduate and Post Graduate. The educational status of these women is showing in
Figure 3. Here recorded data shows that $14.66 \%$ were illiterate or they had no schooling, $16.33 \%$ passed primary, $24 \%$ passed SSC, $25 \%$ passed HSC, $14.33 \%$ was undergraduate, $4.66 \%$ graduate and $1 \%$ was post graduate (Figure 3 ).

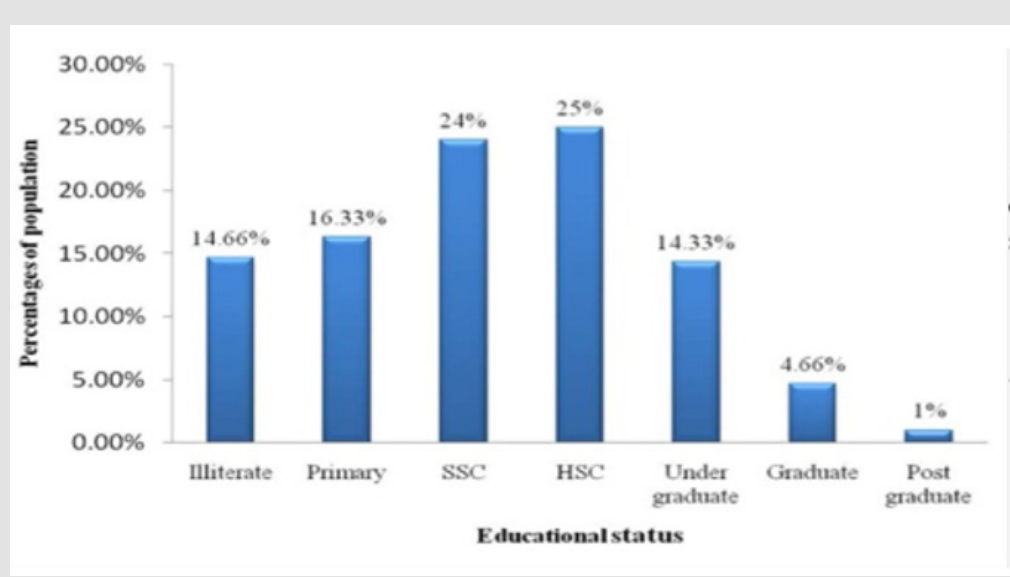

Figure 3: Educational status of sample population.

\section{Obstetric History of Respondents}

We calculated the total obstetric history of our sample population with the abnormality they had during and before pregnancy. The total gravida of the women is given in Figure 4. In recorded data, maximum women (39.66\%) had in their second gravida. The proportion of first grevida (35\%), gravida $3(16 \%)$, gravida 4 (6\%), graviada $5(2.66 \%)$, gravida $6(0.33 \%)$.

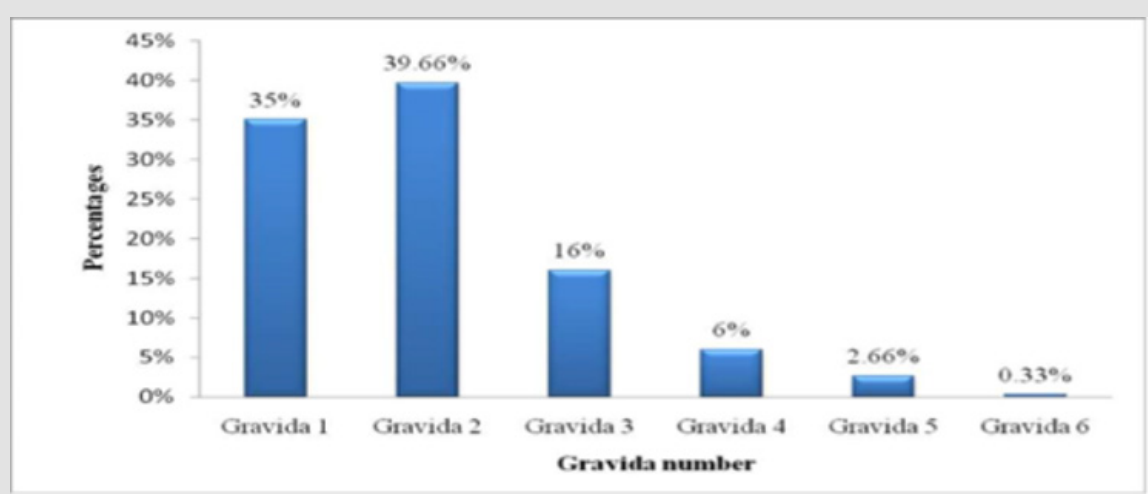

Figure 4: Total number of pregnancy in sample women. 


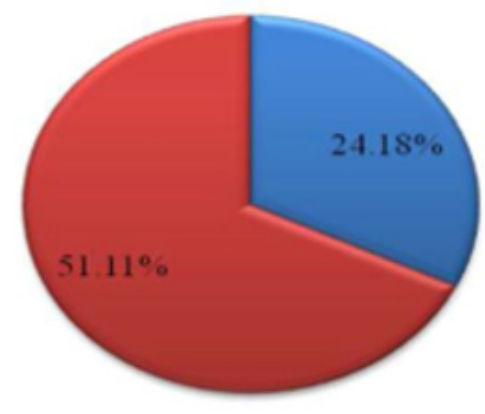

- Pregnancy induced hypertension

uronic hypertension

Figure 5: History of hypertension among the respondent.

\section{Hypertensive Disorder in the Respondents}

For hypertensive disorder we first listed the blood pressure of the patients with $140 / 90$ or above that are showing in Table 1 . About $64.12 \%$ patient in our study had stage 1 hypertension and $28.39 \%$ had stage 2 hypertension. Few patients had pre hypertension and hypertensive crisis. In case of gestational hypertension $51.11 \%$ patient had a previous history of pregnancy hypertension, $24.18 \%$ had chronic hypertension. In Table 2, attempt has been made to show the relation between socio economic, behavioral, clinical

Table 1: Blood pressure ranges of the respondents. and reproductive factors of Preeclampsia patients. Maternal Age, Occupation, Residence, Family history of Preeclampsia, Exercise habit, Family history of CVD, Pre existing Diabetes, Nulliparity, Number of children and H/O Abortion or Miscarriage seem to be a risk factor for developing Preeclampsia during $3^{\text {rd }}$ trimester of pregnancy as p values are less than 0.05. However, Level of Education level has no significant effect on developing Preeclampsia during $3^{\text {rd }}$ trimester as $\mathrm{p}$ value is more than 0.05 , which is not statistically significant.

\begin{tabular}{|c|c|c|}
\hline Stages & Blood pressure & Percentages of the patient \\
\hline Normal blood pressure & Below 120/80mmHg & $0 \%$ \\
\hline Prehypertension & $(120-139) \mathrm{mmHg}$ systolic pressure and (80-89) mmHg diastole Pressure. & $2.46 \%$ \\
\hline Stage 1 & $(140-159) \mathrm{mmHg}$ systolic pressure and (90-99) mmHg diastole pressure & $64.12 \%$ \\
\hline Stage 2 & $\begin{array}{c}\text { Systolic pressure 160 mmHg or higher and diastole pressure 100mmHg or } \\
\text { higher }\end{array}$ & $28.39 \%$ \\
\hline $\begin{array}{c}\text { Hypertensive crisis (emergency are } \\
\text { needed }\end{array}$ & $\begin{array}{c}\text { Systolic pressure is higher than 180mmHg and diastole pressure is higher } \\
\text { than 110 mmHg }\end{array}$ & $4.93 \%$ \\
\hline
\end{tabular}

Table 2: Relationship with socio-demographic variables.

\begin{tabular}{|c|c|c|c|c|c|}
\hline \multirow{2}{*}{ Variables } & \multirow{2}{*}{ Categories } & \multicolumn{2}{|c|}{ Preeclampsia } & \multirow{2}{*}{$x^{2}$ value } & \multirow{2}{*}{ p value } \\
\hline & & $\mathbf{Y}$ & $\mathbf{N}$ & & \\
\hline \multirow{2}{*}{ Maternal Age } & $<=30$ & 43 & 112 & \multirow{2}{*}{130.36} & \multirow{2}{*}{$<0.001$} \\
\hline & $>30$ & 105 & 105 & & \\
\hline \multirow{3}{*}{ Level of Education } & Primary & 49 & 42 & \multirow{3}{*}{3.98} & \multirow{3}{*}{0.14} \\
\hline & Secondary & 69 & 39 & & \\
\hline & Higher Secondary \& Above & 30 & 31 & & \\
\hline \multirow{2}{*}{ Occupation } & Employed & 90 & 39 & \multirow{2}{*}{16.2} & \multirow{2}{*}{$<0.001$} \\
\hline & Unemployed & 58 & 73 & & \\
\hline \multirow{2}{*}{ Residence } & Rural & 27 & 3 & \multirow{2}{*}{13.65} & \multirow{2}{*}{0.0002} \\
\hline & Urban & 121 & 109 & & \\
\hline \multirow{2}{*}{ Family History of Preeclampsia } & No & 84 & 106 & \multirow{2}{*}{44.61} & \multirow{2}{*}{$<0.001$} \\
\hline & Yes & 64 & 6 & & \\
\hline \multirow{2}{*}{ Exercise Habit } & No & 97 & 107 & \multirow{2}{*}{32.19} & \multirow{2}{*}{0.001} \\
\hline & Yes & 51 & 5 & & \\
\hline
\end{tabular}




\begin{tabular}{|c|c|c|c|c|c|}
\hline \multirow{2}{*}{ Family H/O CVD } & $\mathrm{N}$ & 59 & 67 & \multirow{2}{*}{9.38} & \multirow{2}{*}{0.002} \\
\hline & $\mathrm{Y}$ & 89 & 45 & & \\
\hline \multirow{2}{*}{ Pre existing Diabetes } & $\mathrm{N}$ & 64 & 70 & \multirow{2}{*}{8.71} & \multirow{2}{*}{0.003} \\
\hline & Y & 84 & 42 & & \\
\hline \multirow{2}{*}{ Family H/O CVD } & $\mathrm{N}$ & 59 & 67 & \multirow{2}{*}{9.38} & \multirow{2}{*}{0.002} \\
\hline & $\mathrm{Y}$ & 89 & 45 & & \\
\hline \multirow{2}{*}{ Pre existing Diabetes } & $\mathrm{N}$ & 64 & 70 & \multirow{2}{*}{8.71} & \multirow{2}{*}{0.003} \\
\hline & Y & 84 & 42 & & \\
\hline \multirow{2}{*}{ Nulliparity } & No & 43 & 112 & \multirow{2}{*}{16.88} & \multirow{2}{*}{$<0.001$} \\
\hline & Yes & 105 & 0 & & \\
\hline \multirow{3}{*}{ Number of Children } & 1 & 58 & 31 & \multirow{3}{*}{23.27} & \multirow{3}{*}{$<0.001$} \\
\hline & $2+$ & 26 & 3 & & \\
\hline & None & 64 & 787 & & \\
\hline
\end{tabular}

Table 3: Adjusted analysis between variables and Preeclampsia.

\begin{tabular}{|c|c|c|c|c|c|c|}
\hline Variables & Reference & Estimate & OR & LCL & UCL & p-value (5\%) \\
\hline Maternal Age & & 0.69 & 2 & 1.6 & 2.77 & $<0.001$ \\
\hline Level of Education (Secondary) & Primary & 0.13 & 1.4 & 0.41 & 9.25 & 0.9 \\
\hline Level of Education (Higher Secondary \& Above) & Primary & -0.21 & 0.88 & 0.74 & 9.44 & 0.86 \\
\hline Occupation (Unemployed) & Employed & 1.2 & 3.3 & 2.44 & 1.99 & 0.15 \\
\hline Residence (Urban) & Rural & -3.69 & 0.32 & 0.06 & 0.71 & 0.003 \\
\hline Family H/O Preeclampsia (Yes) & No & 2.21 & 9 & 1.3 & 9.14 & 0.03 \\
\hline Exercise Habit (Yes) & No & -1.44 & 0.84 & 1.53 & 1 & 0.06 \\
\hline Family H/O CVD (Yes) & No & 2.14 & 8.5 & 2.5 & 1.43 & 0.09 \\
\hline Preexisting Diabetes (Yes) & No & 0.63 & 1.88 & 1.07 & 1.14 & 0.48 \\
\hline Nulliparity (Yes) & No & -0.42 & 0.36 & 0.43 & 3.38 & 0.61 \\
\hline H/O Abortion \& Miscarriage (Yes) & No & 0.72 & 2.06 & 0.85 & 1.45 & 0.41 \\
\hline Weight gain & & 0.26 & 1.29 & 1.1 & 1.61 & 0.006 \\
\hline
\end{tabular}

\section{Weight Gain and Preeclampsia}

Weight gain during pregnancy has considered as continuous variables. It indicates that, women who gained weight more than $20 \mathrm{~kg}$ during their pregnancy are more prone to develop preeclampsia than the women who gained less than $20 \mathrm{~kg}$ of weight during $3^{\text {rd }}$ trimester. It appears from the box-plot that women whose weight were below $45 \mathrm{~kg}$ during pre pregnancy were less likely to develop preeclampsia during their $3^{\text {rd }}$ trimester of pregnancy than the women whose weight were above $50 \mathrm{~kg}$ (Figure 6). Majority of the patients $(70 \%)$ had persistence headaches, $(11 \%)$ had blurred vision, (67\%) had abdominal pain, and (4\%) had sensitivity of light (Figure 7).
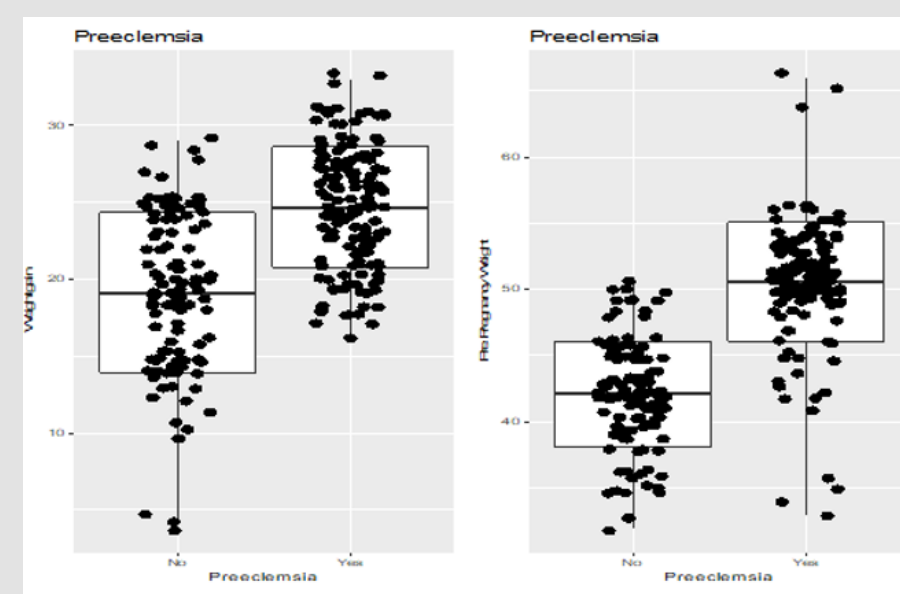

Figure 6: Weight gain during pregnancy and pre-eclampsia. 


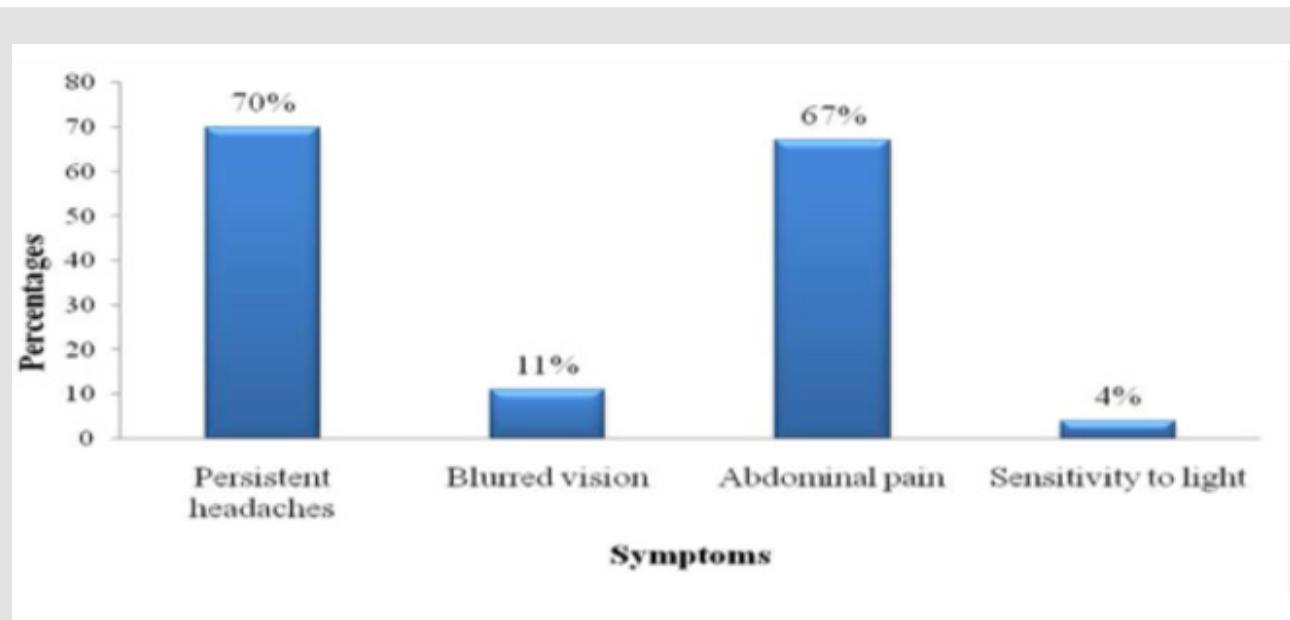

Figure 7: Patients experienced various symptoms.

\section{Symptoms}

Millions of women in developing countries experience life threatening and other serious health problems related to pregnancy or childbirth. Complications of pregnancy and childbirth cause more deaths and disability than any other reproductive health problems (EC/UNFPA, 2000). Age itself has been recognized as a risk factor for developing Preeclampsia during $3^{\text {rd }}$ trimester of pregnancy. According to the present study individuals chance of developing Preeclampsia increases with the age. It has been proved statistically significant ( $p$-value : 0.05 ) in the current study. Teenage pregnancy is associated with maternal anemia, preterm labor, urinary tract infection [15]. We have also found that, in our study population among 51.85\% teenage mothers with various complications, $22.22 \%$ had anemia.

Preterm birth, gestational diabetes, and preeclampsia were more common among older mother [16,17]. Our study has shown that among $75 \%$ older women with complications, $38.77 \%$ had hypertensive disorder. According to the present study Education level has an impact over developing Preeclampsia. Pregnant women with Primary level education are 1.4 times less likely to develop Preeclampsia than who are educated up to Secondary level and $22 \%$ less likely to develop Preeclampsia than higher secondary and above level educated women. However these are not statistically significant as $\mathrm{p}>0.05$. Occupation plays an important role for developing Preeclampsia during 3rd trimester of pregnancy. It can be seen that women who are not associated with any form of employment are developing 3 times more Preeclampsia than who are involved in any kind of employment, which is not statistically significant as p-value is more than 0.05 .

The WHO recommends use of $\mathrm{MgSO}_{4}$ as the standard method of preventing eclampsia in women with severe pre-eclampsia, and for treating eclampsia. Women treated with $\mathrm{MgSO}_{4}$ have a 67 percent reduced, risk of recurrent seizures compared to women treated with other drugs such as diazepam and phenytoin. Despite its proven efficacy, this inexpensive drug is often underutilized for various reasons, including lack of awareness and continued use of outdated methods (diazepam and phenytoin), poor access to supplies, and a lack of sufficient trained personnel to administer $\mathrm{MgSO}_{4}$. The result may serve as a guideline for the public policy planner and the government to take necessary steps against preeclampsia patients. The findings may be beneficial for the health workers and academic purpose. Since preeclampsia is a multi-factorial disease $[18,7,8]$.

It has been observed that Family $\mathrm{H} / \mathrm{O}$ Preeclampsia plays an important role. In this study $\mathrm{p}$ value 0.03 proves that women whose any family member suffered from Preeclampsia are 9 times more likely to develop preeclampsia during their 3rd trimester of pregnancy than the women who has no family history. There are many factors with which the women were more prone to develop hypertension. For examples if a patient had a history of pregnancy induced hypertension or had a history of chronic hypertension or a family relative with a history of hypertension. In this case we had found $51.11 \%$ patient with a previous history of pregnancy induced hypertension, $24.18 \%$ with chronic hypertension and $48.35 \%$ with a family relative with hypertension (Confidential Enquiries into Maternal Deaths, 2001). There are some other related factors which may arise with hypertension. We have found $2.19 \%$ patient with kidney diseases, $23.08 \%$ were facing with rapid or sudden weight gain, $19.78 \%$ have tested urine for presence of protein and $61.54 \%$ experienced of swelling of hands, feet and face [19].

Exercise habit has significant impact over developing preeclampsia. Women who walk at least 15 min per day are $16 \%$ less likely to develop preeclampsia than who does not walk during 3rd trimester of pregnancy, which is statistically significant as $p$ value is 0.06 . It is evident that who has previous history of above mentioned illness are 1.8 times more likely to develop preeclampsia than the women who do not have. This statistically is not significant as $\mathrm{p}<0.48$.

Also, women who have previous $\mathrm{H} / \mathrm{O}$ abortion or miscarriage are 2 times more likely to develop preeclampsia than who has not such history. However, these are not statistically significant as $p$ 
value is more than 0.05 . Weight gain is statistically significantly associated with developing preeclampsia during 3rd trimester of pregnancy as p-value is 0.006 . Either depression or anxiety, or both, were associated with increased risk (OR 3.1; 95\% CI 1.4, 6.9) for preeclampsia. Bacterial vaginosis together with depression was associated with increased risk (OR 5.3; 95\% CI 1.8, 15.0) for preeclampsia [20]. In a study showed that the overall preeclampsia rate was $3.1 \%$ and the incidence increased sharply with gestation; early- and late-onset preeclampsia rates were $0.38 \%$ and $2.72 \%$, respectively [21].

In our study, prevalence in the age group $\geq 25$ years was found to be significantly higher (9.9\%) as compared to age group $<25$ (5.9\%). In accordance with our study, it is identified that the risk of developing PIH tends to increase with maternal age. In comparison with women aged 20-25 years, the odds ratio (OR) was 3.5 in women aged 26-30 years and 4.2 in those aged $>30$ years. The present study revealed no significant association between occupation and hypertension in pregnancy $(\mathrm{P}=0.146)$. Few other studies also reported a non-significant association between occupation and hypertension. [22] found out in their study that among the 763 women, 193 (25 percent) had preeclampsia. The frequency of preeclampsia was not affected by the presence of proteinuria at base line. found out in their study that among the 763 women, 193 (25 percent) had preeclampsia. The frequency of preeclampsia was not affected by the presence of proteinuria at base line [23-25].

\section{Conclusion and Recommendation}

From the result of this study, it can be concluded that Among the respondent $44 \%$ presented with preeclampsia and the associated risk factors included Socio-economic Factors, Behavioral Factors, Clinical Factors and Reproductive Factors. There is evidence that suggests individual with these factors remain at a high risk for developing preeclampsia. Presence of hypertension can be predicted by noticing some signs or symptoms. Proper antenatal care remains the important part of prevention. Hence there is a need to develop an integrated model for the estimation of patient specific risk factors for the development of preeclampsia on the basis of maternal demographic, socio-economic, obstetrics, nutritional and anthropometric parameters.

\section{References}

1. Davies AM, Czaczkes JW, Sadovsky E, Prywes R, Weiskopf P, et al. (1989) Toxemia of pregnancy in Jerusalem I. Epidemiological studies of a total community.Isr J Med Sci 6(2): 253-266.

2. Dukler D, Porath A, Bashiri A, Erez O, Mazor M (2001) Remote prognosis of primiparous women with preeclampsia. Eur J Obstet Gynecol Reprod Biol 96(1): 69-74.

3. Eskenazi B, Fenster L, Sidney SA (1991) Multivariate analysis of risk factors for preeclampsia. JAMA 266(2): 237-241.

4. Hartikainen A, Aliharmi RH, Rantakallio PT (2012) A cohort study of epidemiological associations and outcomes of pregnancies with hypertensive disorders. Hypertens Pregnancy 17(1): 31-41.
5. Higgins JPT, Thompson SG (2002) Quantifying heterogeneity in a metaanalysis. Stat Med 21(11): 1539-1558.

6. Lawoyin TO, Ani F (2002) Epidemiologic aspects of pre-eclampsia in Saudi Arabia. East Afr Med J 73(6): 404-406.

7. Lee CJ, Hsieh TT, Chiu TH, Chen KC, Lo LM, et al. (2000) Risk factors for pre-eclampsia in an Asian population. Int J Gynecol Obstet 70: 327-333.

8. Makkonen N, Heinonen S, Kirkinen P (2000) Obstetric prognosis in second pregnancy after preeclampsia in first pregnancy. Hypertens Pregnancy 19(2): 173-181.

9. Khan KS, Daya (1996) Plasma glucose and pre-eclampsia. Int J Gynecol Obstet 53(2): 111-116.

10. Sibai BM, El Nazer A, Gonzalez-Ruiz A (2005) Severe preeclampsiaeclampsia in young primigravid women: subsequent pregnancy outcome and remote prognosis. Am J Obstet Gynecol 155(5): 1011-1016.

11. (2011) World Health Organization. International Collaborative Study of Hypertensive Disorders of Pregnancy Geographic variation in the incidence of hypertension in pregnancy. Am J Obst Gynecol 158(1): 8083.

12. Odegard RA, Vatten LJ, Nilsen ST, Salvesen KA, Austgulen R (2000) Risk factors and clinical manifestations of pre-eclampsia. Br J Obstet Gynaecol 107(11): 1410-1416.

13. Saftlas AF, Olson DR, Franks AL, Atrash HK, Pokras R (1990) Epidemiology of preeclampsia and eclampsia in the United states, 1979-1986. Am J Obstet Gynecol 163(2): 460-465.

14. Campbell DM, MacGillivray I, Carr-Hill R (1985) Pre-eclampsia in second pregnancy. Br J Obstet Gynaecol 92(2): 131-140.

15. Matthys LA, Coppage KH, Lambers DS, Barton JR, Sibai BM (2004) Delayed postpartum preclampsia: An experience of 151 cases. Am J Obstet Gynecol 190(5): 1464-1466.

16. Stone JL, Lockwood CJ, Berkowitz GS, Alvarez M, Lapinski R, et al. (2004) Risk factors for severe preeclampsia. Obstet Gynecol 83(3): 357-361.

17. Arngrimsson R, Bjornsson S, Geirsson RT, Bjornsson H, Walker JJ, et al. (2002) Genetic and familial predisposition to eclampsia and preeclampsia in a defined population. Br J Obstet Gynaecol 97(9): 762-769.

18. Sutherland A, Cooper DW, Howie PW, Liston WA, MacGillivray I (1981) The incidence of severe pre-eclampsia amongst mothers and mothersin-law of pre-eclamptics and controls. Br J Obstet Gynaecol 88(8): 785791.

19. Chen CL, Cheng Y, Wang PH, Juang CM, Chiu LM, et al. (2000) Review of pre-eclampsia in Taiwan: a multi-institutional study. Zhonghua Yi Xue Za Zhi (Taipei) 63: 869-875.

20. Conde-Agudelo A, Althabe F, Belizan JM, Kafury-Goeta AC (2002) Cigarette smoking during pregnancy and risk of pre-eclampsia: a systematic review. Am J Obstet Gynecol 181(4): 1026-1035.

21. Cincotta RB, Brennecke SP (2014) Family history of pre-eclampsia as a predictor for pre-eclampsia in primigravidas. Int J Gynaecol Obstet 60(1): 23-27.

22. Banias BB, Devoe LD, Nolan TE (2005) Severe preeclampsia in preterm pregnancy between 26- and 32-weeks' gestation. Am J Perinatol 9(5-6): 357-360.

23. Bianco A, Stone J, Lynch L, Lapinski R, Berkowitz G, et al. (2001) Pregnancy outcome at age 40 and older. Obstet Gynecol 87(6): 917-922.

24. (2001) Confidential Enquiries into Maternal Deaths. Why mothers die 1997-1999. The fifth report of the confidential enquiries into maternal deaths in the United Kingdom. London:Royal College of Obstetricians and Gynaecologists Press.

25. Coonrod DV, Hickok DE, Zhu K, Easterling TR, Daling JR (1995) Risk factors for preeclampsia in twin pregnancies: a population-based cohort study. Obstet Gynecol 85(5): 645-650. 
ISSN: 2574-1241

DOI: 10.26717/BJSTR.2021.33.005445

Hamida Khanum. Biomed J Sci \& Tech Res

(C) $(7)$ This work is licensed under Creative BY Commons Attribution 4.0 License

Submission Link: https://biomedres.us/submit-manuscript.php

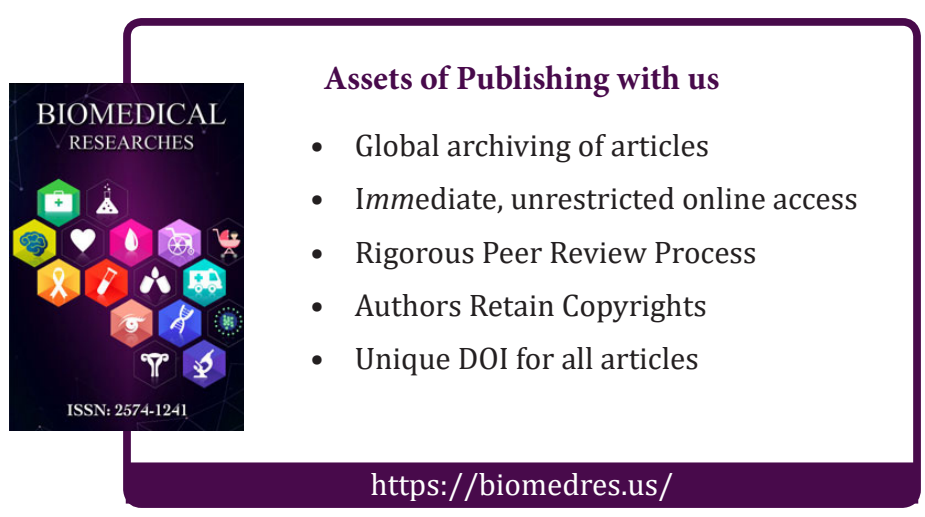

